\title{
A tiered ecological risk assessment of three chlorophenols in Chinese surface waters
}

\author{
Xiaowei Jin • Jijun Gao • Jinmiao Zha • Yiping Xu • \\ Zijian Wang • John P. Giesy $•$ Kristine L. Richardson
}

Received: 1 September 2011 /Accepted: 2 November 2011 / Published online: 18 November 2011

(C) Springer-Verlag 2011

\begin{abstract}
Introduction The ecological risks posed by three chlorophenols (CPs), 2,4-dichlorophenol (2,4-DCP), 2,4,6trichlorophenol (2,4,6-TCP), and pentachlorophenol (PCP) in Chinese surface waters were assessed.

Materials and methods This was achieved by applying a tiered ecological risk assessment (ERA) approach ranging from deterministic methods to probabilistic options to measured concentrations of CPs in surface water of seven major watersheds and three drainage regions in China and the chronic toxicity data for indigenous Chinese species.
\end{abstract}

Responsible editor: Philippe Garrigues

Electronic supplementary material The online version of this article (doi:10.1007/s11356-011-0660-8) contains supplementary material, which is available to authorized users.

X. Jin $\cdot$ J. Gao $\cdot$ J. Zha $\cdot$ Y. Xu $\cdot$ Z. Wang $(\bowtie)$

State Key Laboratory of Environmental Aquatic Chemistry,

Research Center for Eco-Environmental Sciences,

Chinese Academy of Sciences,

Shuangqing Rd 18, Haidian District,

Beijing 100085, People's Republic of China

e-mail: wangzj@rcees.ac.cn

J. Gao

Department of Water Environment Research,

China Institute of Water Resource and Hydropower Research,

Beijing 100038, China

J. P. Giesy

Department of Veterinary Biomedical Sciences and Toxicology

Centre, University of Saskatchewan,

Saskatoon, SK, Canada

J. P. Giesy

Department of Zoology, Center for Integrative Toxicology,

Michigan State University,

East Lansing, MI, USA
Results and discussion The results show that the risks of three chlorophenols are ranked $\mathrm{PCP}>2,4-\mathrm{DCP} \approx 2,4,6-\mathrm{TCP}$. PCP posed little ecological risk while 2,4-DCP and 2,4,6TCP posed negligible or de minimis risk in Chinese surface water. However, the risks varied with different river basins, for example, PCP posed some ecological risk in the Yangtze, Huaihe, and Pearl Rivers. The magnitude of 2,4DCP and 2,4,6-TCP pollution in North China was more serious than that in South China.

Conclusion The probabilistic risk assessment approach, which can provide more information for risk managers

\author{
J. P. Giesy \\ Department of Biology and Chemistry, \\ City University of Hong Kong, \\ Kowloon, Hong Kong, China
}

\section{K. L. Richardson}

Environmental Toxicology Program,

Department of Environmental Sciences,

University of California,

Riverside, CA, USA 
and decision makers, was favored over the screening-level single-value estimate method. However, the results from all tiers of the ERA methods in the framework were consistent with each other.

Keywords Probabilistic ecological risk assessment. Hazard quotient $\cdot$ Surface water $\cdot$ Statistics $\cdot$ Toxicity $\cdot$ Asia

\section{Introduction}

Chlorophenols are synthetic organic compounds, used as synthesis intermediates in dyestuffs and pesticides or as biocides themselves. As industrial waste, they are direct pollutants in the environment, and due to their relative solubility and persistence, are detectable in rivers, ponds, and soil (Czaplicka 2004; Gao et al. 2008). Furthermore, chlorophenols can be produced as transformation products of more complex molecules such as phenoxyacetic acids and chlorobenzenes. Chlorophenols occur extensively in surface waters (Asplund and Grimvall 1991; Grimvall 1995). Some chlorophenols, such as 2,4-dichlorophenol (2,4-DCP), 2,4,6-trichlorophenol (2,4,6-TCP), and pentachlorophenol (PCP), have been detected in watersheds and drainage areas of China at relatively great concentrations (Gao et al. 2008; Zhong et al. 2010). PCP and 2,4-DCP are endocrine disruptors (Zhang et al. 2004; Zha et al. 2006), while PCP and its sodium salt are recognized as a class $2 \mathrm{~B}$ carcinogen by the International Agency for Research on Cancer (Ge et al. 2007). Due to their aquatic toxicity, resistance to degradation, and potential for bioaccumulation, 2,4-DCP, 2,4,6-TCP, and PCP are priority pollutants in aquatic environments of the USA as well as China (USEPA 1991; Xia et al. 2004). Analyzing the ecological risk of these chemicals is crucial to the protection of aquatic organisms and the surface water environment of China.

The most rudimentary approach to assessing the potential risks of chemicals is to compare the exposures, measured or predicted exposure concentrations, with concentrations associate with adverse effects, expressed as the predicted no-observed effect concentrations, PNEC, derived from dose-response relationships. The simplest comparison is a single-point estimate, usually expressed as the hazard quotient (HQ), which is the measured or estimated environmental concentration divided by the toxicant reference value (Solomon et al. 2000; Wang et al. 2002). Although, it is because of its simplicity and effectiveness, the HQ approach is widely used; its use is only appropriate for conservative screening-level risk assessment and for the early stages or tiers of risk assessment. Because potential risk represents a likelihood or probability of occurrence, it cannot be established from point estimates, such as the HQ
(SETAC 1994; Bartell et al. 2000; Solomon et al. 2000). Probabilistic ecological risk assessments (PERAs), which qualify and quantify ecological risks through exposure and effect probability distributions, are regarded as an improvement on the HQ approach and, thus, recommended for later tiers in the ecological risk assessment (ERA) process (Solomon 1996). Because PERAs can better describe the likelihood of exceeding the effect thresholds and the risk of adverse effects (Solomon and Sibley 2002), this approach has been adopted by a number of researchers (Giesy et al. 1999; Hall et al. 2000; Zolezzi et al. 2005; Brain et al. 2006; Hunt et al. 2010). To obtain more reliable results for decision-making processes on site-specific contamination, some researchers and scientific institutions have suggested the use of a tiered approach, ranging from simple deterministic methods to probabilistic methods, for risk characterization, (Solomon et al. 2000; Zolezzi et al. 2005; Wang et al. 2009).

Hazard identification and risk assessment of chemicals are based primarily on toxicity thresholds of organisms. Toxicity thresholds, which are determined from chronic studies, such as the no observed effect concentrations (NOECs) are preferred when deriving toxicity thresholds in ERA (Pennington 2003). However, there is often a lack of chronic toxicity data because of the high cost and time required to perform such studies. This is especially true for local species required for site-specific ERAs. An alternative approach is the use of acute toxicity data $\left(\mathrm{LC}_{50}\right.$ or $\left.\mathrm{EC}_{50}\right)$ and application of an appropriate acute to chronic ratio (ACR) to predict concentrations that will not cause adverse effects during long-term chronic exposures (Chen 2005; Wang et al. 2009). However, the use of ACRs has been criticized (Chapman et al. 1998; Roex et al. 2000; Isnard et al. 2001). In some cases, average ACRs can be inadequate to extrapolate accurately from acute to chronic values (Brix et al. 2001; Besser et al. 2005). In addition, the toxicity data used in Chinese site-specific ERAs are mainly data for nonnative species from toxicity databases (e.g., ECOTOX) due to the paucity of toxicity data available for local species (Wang et al. 2002, 2009; Chen 2005; Zhong et al. 2010). However, the potential use of toxicity information for nonnative species for description of a local problem is controversial (Davies et al. 1994).

The objective of the present study was to undertake an aquatic ERA that would provide a realistic assessment of the risk posed by three chlorophenols $(2,4-D C P$, 2,4,6-TCP and PCP) found in surface waters throughout China. This was achieved by applying a tiered ERA approach consisting of several probabilistic options, concentrations of chlorophenols from nationwide surface water monitoring program, and chronic toxicity data for indigenous Chinese species from laboratory experiments and published literature. 


\section{Materials and methods}

\subsection{Exposure assessment}

Samples were collected from the seven major watersheds of China, including the Yangtze, Yellow, Pearl, Songhuajiang, Liaohe, Haihe, and Huaihe rivers. Samples were also collected from other smaller rivers in the southeast, northwest, and southwest regions of China. The total number of locations was 623 consisting of 217 reservoirs and 406 rivers and lakes. A global positioning system was used to locate the sampling locations. China was divided into ten main areas corresponding to different watersheds and drainage areas (Fig. 1). Sampling was conducted once each location over a 1-year period (2003 and 2004).

Samples were collected in chemically cleaned glass sampling bottles, refrigerated, and shipped to the laboratory. Aliquots of the sample $(5.0 \mathrm{l})$ were filtered through a $0.45-\mu \mathrm{m}$ glass fiber filter under vacuum and then surrogate standards (2-chlorophenol-3,4,5,6- $d_{4}$ and 2,4-dimethylphenol$\left.3,5,6-d_{3}\right)$ were added. Chlorophenols were extracted by solid phase extraction following published procedures (Zhou et al. 2000; Zhang et al. 2002). An Agilent 6890 GC coupled to a $5973 \mathrm{~N}$ MS detector in selected ion mode was used for 2,4-dichlorophenol, 2,4,6-trichlorophenol, and pentachlorophenol analysis (Gao et al. 2008). The method detection limits (MDLs) ranged from $1.1 \mathrm{ng} \mathrm{L}^{-1}$ for 2,4DCP and PCP to $1.4 \mathrm{ng} \mathrm{L}{ }^{-1}$ for 2,4,6-TCP. Recoveries of spikes of 2,4-CP, 2,4,6-TCP and PCP were between $84.7 \%$ and $107.3 \%$ and were within the acceptable criteria. For statistical analyses, values that were less than the MDL were replaced with a surrogate value equal to half the MDL.

\subsection{Effect assessment}

Chronic toxicity values for indigenous aquatic species, representing different trophic levels, were obtained from laboratory experiments and published literature. Toxicity data were considered "Indigenous" if test organisms were endemic to natural ecosystems of China and if tests were conducted under conditions appropriate for Chinese environmental conditions. At least ten organisms belonging to four taxonomic groups were selected to characterize the effect of three chlorophenols on organisms in surface waters of China. Criteria used in selecting test species were primarily their regional relevance, size of distribution, economic significance, and adaptability to laboratory conditions.

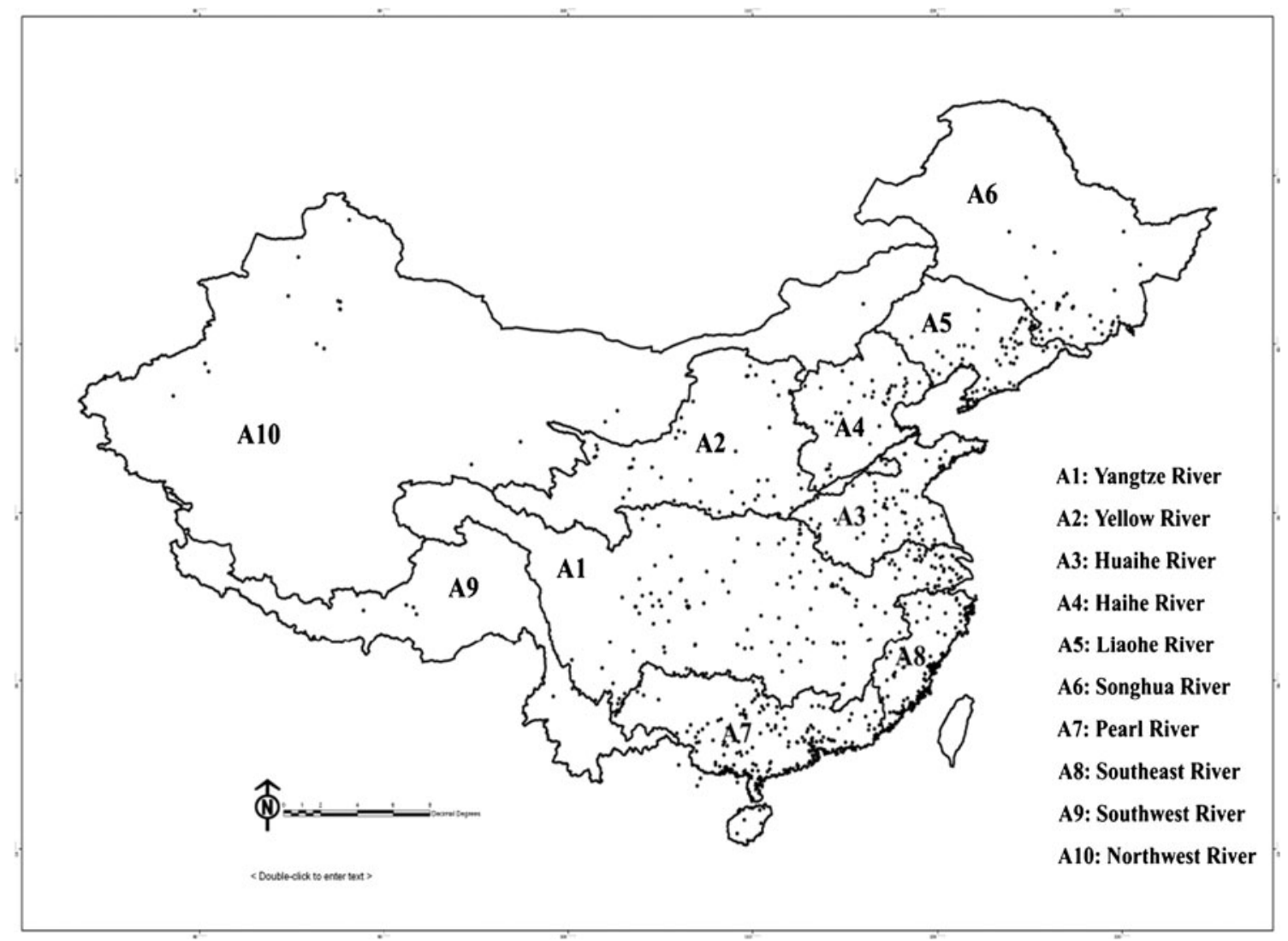

Fig. 1 Sampling locations map of three chlorophenols in Chinese surface water 
The laboratory experiments were conducted between March 2009 and January 2010. Six indigenous speciestwo benthic invertebrates (Asian clam Corbicula fluminea and Freshwater shrimp Macrobrachium superbum), three fishes (black carp, Mylopharyngodon piceus; smallscale yellowfin, Plagiognathops microlepis; and Culter alburnus, Erythroculter ilishaeformis), and one hydrophyte (greater duckweed Soirodela polyrhiza) — were selected based on the aforementioned criteria. Subchronic exposures of three chlorophenols to six indigenous species were conducted in static renewal tests with daily replacements. Detailed test methods and endpoints have been provided by Jin et al. (2011a, b, c) but portions of data are novel to this study. Additional chronic toxicity data for indigenous species exposed to the three chlorophenols were collected from published literature and government documents following the principles of accuracy, relevance, and reliability (Klimisch et al. 1997). When a NOEC was not available, maximum allowable toxicant concentration or lowest observed effect concentration or $\mathrm{EC}_{\mathrm{x}}$ was used (and noted). If more than one dataset for the same species was available, the toxicity value for the most sensitive end point was chosen. In the case of multiple data on the same endpoint and species, the geometric mean was used. Toxicity data used for the species sensitivity distributions (SSD) calculation are reported in the Supporting Information (Table S2, S3, and S4).

SSDs were constructed by fitting cumulative probability distributions that plotted the concentration associated with eliciting a particular response from a particular species as a function of rank-assigned centile (Aldenberg and Slob 1993; Wheeler et al. 2002). Usually, a point estimate known as the $\mathrm{HC}_{5}$ (hazardous concentration for $5 \%$ of species) is calculated from the SSD. This concentration is predicted to exceed no more than $5 \%$ of species effect levels. In this study, a log-normal distribution model was fitted to a minimum of ten data points and the fit of the model was evaluated using Kolmogorov-Smirnov test. The $\mathrm{HC}_{5}$ values were then derived from these models (ETX 2.0, RIVM) and the final PNECs were calculated as the derived $\mathrm{HC}_{5}$ with a $50 \%$ uncertainty divided by a factor 5 (ECB 2003).

\subsection{Tiered risk characterization}

The risk assessment process used in this study was a tiered approach following published methods (ECOFRAM 1999; Zolezzi et al. 2005; Wang et al. 2009) and consisting on four levels - deterministic, etc.

Level 1 deterministic HQs were calculated by dividing measured environmental concentrations (MECs) with PNECs. For comparison, two MEC values were used for HQ calculations, the mean, which was calculated by both excluding and replacing the values less than the MDL, and the maximum concentrations of 2,4-DCP, 2,4,6-TCP, and PCP, within an area, respectively.

The level 2 method assessed the probability that measured concentrations exceeded point-estimate effect concentrations by comparing exposure concentration distributions with PNEC values. Usually, the Kolmogorov-Smirnov test was applied to evaluate the normal distribution of raw or log-transformed data from the exposure concentrations (concentrations above the MDL). The statistical summary of the exposure distributions are reported in the Supporting Information (Table S1).

Level 3 utilized both exposure and effect distributions. First, the margin of safety $\left(\mathrm{MOS}_{10}\right)$ was calculated as the ratio of the 90th centile for the exposure distribution to the 10th centile for SSD after log-normal transformation of the chronic species toxicity data and aquatic contaminants concentrations (Solomon 1996). When the 90th centile for exposure was greater than the 10th percentile for toxicity, the margin of safety was less than 1.0, which indicated a significant risk to aquatic organisms. Margins of safety greater than 1.0 indicated that the distributions did not overlap and thus minimal risk to aquatic organisms. In addition, the exceedance probability function (EXF, calculated as 100-cumulative distribution function) and the SSD were used to generate a joint probability curve (JPC), which describes the probability of a particular set of exposure conditions occurring relative to the number of taxa that would be affected (Solomon et al. 2000; Zolezzi et al. 2005; Wang et al. 2009).

The level 4 method involved distribution-based quotients (DBQs), which expressed the risk as the probability of exceeding preselected HQs (Zolezzi et al. 2005). The Monte Carlo technique (Crystal Ball 2000 v.5.2.) was used to sample randomly values from distributions of exposure and toxicity (20,000 simulations) and to generate a distribution expressing the probability of the quotients to be exceeded.

\section{Results and discussion}

\subsection{Exposure assessment}

The statistical summary of individual chlorophenol concentrations in surface waters from China is shown in the Supporting Information (Table S1). Rates of detection of 2,4-dichlorophenol, 2,4,6-trichlorophenol, and pentachlorophenol were $50.2 \%, 50.2 \%$, and $80.9 \%$, respectively. Concentrations for 2,4-dichlorophenol ranged from $<1.1$ to $19,960.0 \mathrm{ng} \mathrm{L}^{-1}$, with a median of $23.8 \mathrm{ng} \mathrm{L}^{-1}$. The range of 2,4,6-trichlorophenol was from $<1.4$ to $28,650.0 \mathrm{ng} \mathrm{L}^{-1}$, with a median value of $13.5 \mathrm{ng} \mathrm{L}^{-1}$. 
Concentrations of pentachlorophenol ranged from $<1.1$ to $594.0 \mathrm{ng} \mathrm{L}^{-1}$, with a median value of $60.7 \mathrm{ng} \mathrm{L}^{-1}$. The median concentration and rate of detection for pentachlorophenol were both greater than those for 2,4-dichlorophenol and 2,4,6-trichlorophenol. Concentrations of chlorophenols surface waters of China were similar to those of chlorophenols in other places in the world (Carey et al. 1988; Veningerova et al. 1998; Rawn et al. 1999).

For the seven major watersheds and three drainage regions, 2,4-dichlorophenol and 2,4,6-trichlorophenol were more frequently detected at greater concentrations in the rivers of North China (Yellow, Huaihe, Haihe, Liaohe, and Northwest rivers), while pentachlorophenol concentrations were greater in the Yangtze River watershed. Pentachlorophenol was used in China for years as a molluscacide to kill oncomelania, especially in the Yangtze River watershed, which might be the reason for the great concentrations of pentachlorophenol in the Yangtze River (Gao et al. 2008). Concentrations of all three chlorophenols were less than the MDL in water from all five locations on the Southwest River, and were greater than the MDL in water from all 39 locations on the Haihe River.

The distribution of each of the three chlorophenols in each of the ten surface waters was tested for normality as raw or log-transformed data (concentrations greater than the MDL) by use of the Kolmogorov-Smirnov test. All data were log-normally distributed, except for the Southwest River for which normality could not be assessed because concentrations of all three chlorophenols were less than the MDL in water from all five locations.

\subsection{Effect assessment}

A total of 12,11, and 11 subchronic toxicity data sets of 2,4-DCP, 2,4,6-TCP, and PCP, respectively, exposure to indigenous Chinese species were collected. The NOECs ranged from $50 \mu \mathrm{g} \mathrm{L}^{-1}$ (fish larval growth test) to $5,000 \mu \mathrm{g} \mathrm{L}^{-1}$ (alga growth test), $50 \mu \mathrm{g} \mathrm{L}^{-1}$ (fish larval growth test) to $2.0 \times 10^{3} \mu \mathrm{g} \mathrm{L}^{-1}$ (bivalve survival test) and $10 \mu \mathrm{g} \mathrm{L}^{-1}$ (fish larval growth test) to $9.7 \times 10^{1} \mu \mathrm{g} \mathrm{L}^{-1}$ (alga growth test) for 2,4-DCP, 2,4,6-TCP, and PCP, respectively (Supporting Information Table S2, S3, and S4). 2,4-DCP, 2,4,6-TCP, and PCP are toxic to native freshwater aquatic organisms. Among the species tested, fishes were more sensitive than were aquatic macro invertebrates and the aquatic algae were the least sensitive. Among the chlorophenols tested, PCP was more toxic than 2,4DCP or 2,4,6-TCP. This result is consistent with the fact that toxicity of chlorophenols depends on the number and position of chlorine atoms relative to the hydroxyl group (Czaplicka 2004).

Toxicity data for the three chlorophenols were determined, based on results of the Kolmogorov-Smirnov test $(p<0.05$, to be normally distributed). The calculated PNECs for each chlorophenol, which ranged from 1.4 to $9.4 \mu \mathrm{g} \mathrm{L}^{-1}$, are given (Table 1). Derivation of PNEC values in the EU risk assessment procedure uses either the application of an assessment factor of 10-1000 on the least NOEC or the $\mathrm{HC}_{5}$ (based in the SSD approach) divided by a safety factor (ECB 2003). Assessment factors are recognized as a conservative approach for dealing with uncertainty in assessing risks posed by chemicals (Chapman et al. 1998). Specifically in the present study, because the NOEC values determined in the present study for these species were all less than the reported criterion continuous concentration (CCC) values, the reported CCC values of 212 and $226 \mu \mathrm{g} \mathrm{L}^{-1}$ for 2,4-DCP and 2,4,6-TCP (Yin et al. 2003a, b) would not provide enough protection to native aquatic species including $M$. superbum, $M$. piceus, and P. microlepis (Jin et al. 2011a, b).

\subsection{Risk characterization}

Level 1 The HQs of 2,4-DCP, 2,4,6-TCP, and PCP in Chinese surface waters are shown (Fig. 2). Risk was assessed using either the mean (including MDL/2 for values less than the MDL) or maximum concentration for each chlorophenol in each surface water. For assessments based on the mean, although three chlorophenols with HQs less than one in all sample areas, a more rigorous criterion
Table 1 Chronic toxicity data for three chlorophenols: lognormal distribution, calculated means, standard deviations and PNEC values

\begin{tabular}{|c|c|c|c|}
\hline & \multicolumn{3}{|c|}{ Log-transformed NOECs } \\
\hline & 2,4-DCP & $2,4,6-\mathrm{TCP}$ & PCP \\
\hline Mean $\left(\mu \mathrm{g} \mathrm{L}^{-1}\right)$ & $7.9 \times 10^{2}$ & $5.5 \times 10^{2}$ & 34 \\
\hline $\mathrm{SD}$ & $1.4 \times 10^{3}$ & $5.9 \times 10^{2}$ & 26 \\
\hline Normal distribution test (log-transformation) & 0.837 & 0.433 & 0.540 \\
\hline Number of samples & 12 & 10 & 12 \\
\hline 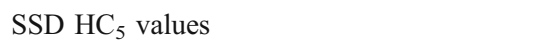 & $44(12-97)$ & $47(13-99)$ & $7.2(3.2-11.6)$ \\
\hline $\mathrm{PNEC}\left(\mathrm{HC}_{5} / 5\right)$ & 8.80 & 9.40 & 1.44 \\
\hline
\end{tabular}


Fig. 2 HQs calculated by dividing averages (a) and maximum (b) concentrations respectively by PNECs of three chlorophenols
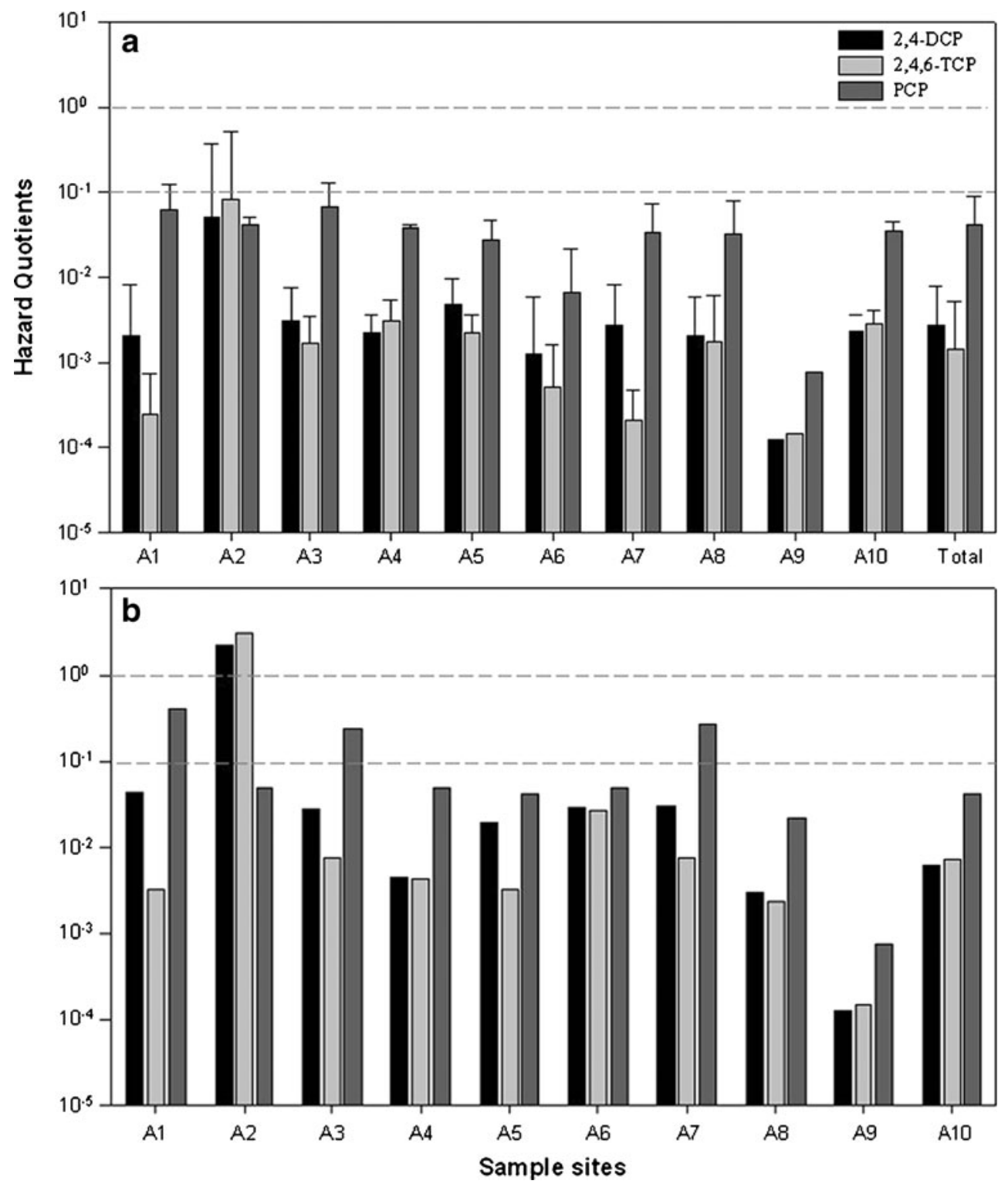

(e.g., 0.1) was selected because chlorophenols are not only hazardous, but also persistent in aquatic environments. Therefore, in the present study, an HQ greater than 0.1 was assumed to indicate a potential risk. The results indicated a potential ecological risk from 2,4-DCP and 2,4,6-TCP in the Yellow River, and from PCP in the Yangtze River (Fig. 2a). The worst-case assessment, obtained through the comparison of the maximum concentration with the PNEC, suggested a slight potential for adverse effects to aquatic organisms with all quotients less than 1.0, except for Yellow River for which values were as great as 3.05, and HQs for PCP were also greater than 0.1 in the Yangtze, Huaihe, and Pearl rivers (Fig. 2b). Among the chlorophenols considered, HQ values for PCP were greater than those for both 2,4-DCP and 2,4,6-TCP. Thus, PCP, which is a common pollutant in Chinese surface waters represents as greater risk than the other two chlorophenols. Because HQ values cannot account for the spatial temporal variability of concentrations and the probability and magnitude of ecological effects, this method is only appropriate for conservative screening-level risk assessments and only for the early stages or tiers of the risk assessment.

Level 2 Comparisons of exposure distributions (for the entire study region) and effect data indicated that the probabilities of exceeding the PNECs were negligible$0.3 \%, 0.3 \%$, and zero for 2,4-DCP, 2,4,6-TCP, and PCP, respectively. The probabilities of exceeding a PNEC/10 were $0.3 \%, 1.0 \%$, and $13.2 \%$ for $2,4-\mathrm{DCP}, 2,4,6-\mathrm{TCP}$, and PCP, respectively. Probability distributions were also obtained for each area. The greatest concentrations of 2,4DCP and 2,4,6-TCP, were observed in the Yellow River 
with probabilities of $2.1 \%$ and $2.1 \%$ of exceeding PNEC value and $2.1 \%$ and $6.3 \%$ of exceeding $\mathrm{PNEC} / 10$ value. Comparison of the distribution of concentrations of PCP resulted in no single area exceeding the PNECs, but five rivers, Yangtze, Huaihe, Pearl, Southeast, and Northwest Rivers, had probabilities of exceeding PNEC/10 value of $21.5 \%, 22.2 \%, 7.6 \%, 9.5 \%$, and $16.7 \%$, respectively.

Level $3 \mathrm{MOS}_{10}$ indicates the factor between the 90th centile of exposure and the 10th centile of effects (here, NOEC). The less the $\mathrm{MOS}_{10}$, the greater the risk, $\mathrm{MOS}_{10}$ for the three chlorophenols are listed in Table 2. PCP $\left(\mathrm{MOS}_{10}=\right.$ 10.0) has a greater potential risk than 2,4-DCP $\left(\mathrm{MOS}_{10}=\right.$ 146.7) and 2,4,6-TCP $\left(\mathrm{MOS}_{10}=313.3\right)$. However, the $\mathrm{MOS}_{10}$ values for all three chlorophenols were all greater than 1.0, which indicates that the NOEC were exceeded in some portions of the area (Fig. 3). The $\mathrm{MOS}_{10}$ for PCP was near to 1.0 , which indicates that PCP in surface waters of China presents a potential risk, especially in the Huaihe, Yangtze, and Pearl Rivers, which had $\mathrm{MOS}_{10}$ values of $6.02,8.42$, and 11.4, respectively. The MOS curves do not provide the absolute risk for chemicals, but rather provide the risk assessor and risk manager with information on relative risk.

JPCs resulting from direct comparison of EXF and SSD offer a better representation of the overall risk (Fig. 4). The $x$-axis of the JPC represents the intensity of effects, while the $y$-axis represents their probability. Each point on the curve represents both the probability that the chosen proportion of species will be affected and the frequency with which that level of effect would be exceeded. The closer the JPC is to the axes, the less the probability of adverse effects (Solomon et al. 2000). In the present study,

Table $2 \mathrm{MOS}_{10}$ calculated from 90th percentile of exposure and the 10 th percentile of effects for three chlorophenols

$\mathrm{MOS}_{10}$

2,4-dichlorophenol 2,4,6-trichlorophenol Pentachlorophenol

\begin{tabular}{lcrr}
\hline A1 & 312.06 & $2,350.00$ & 8.42 \\
A2 & 171.88 & 52.81 & 24.00 \\
A3 & 125.00 & 313.33 & 6.02 \\
A4 & 220.00 & 235.00 & 28.80 \\
A5 & 105.77 & 313.33 & 48.00 \\
A6 & 275.00 & 293.75 & 24.00 \\
A7 & 118.44 & 313.33 & 11.42 \\
A8 & $1,060.24$ & $1,958.33$ & 90.56 \\
A9 & - & - & - \\
A10 & 266.67 & 313.33 & 24.00 \\
Total & 146.67 & 313.33 & 10.00 \\
\hline
\end{tabular}

probabilities of exceeding the NOEC for $5 \%$ of the species were near zero for all three chlorophenols. Therefore, the JPC curves almost overlap with the $x$-axis (Fig. 4). In order to obtain a visual indication of the risk indicated by JPCs, it was necessary to apply safety factors of 10 or 100 to the NOEC.

The probability of exceeding the NOEC/10 for $1-5 \%$ of the species ranged from $2.0 \times 10^{-4}$ to $0.02 \%, 0.08-0.10 \%$, and $0.08-1.74 \%$ for $2,4-\mathrm{DCP}, 2,4,6-\mathrm{TCP}$, and PCP, respectively. When a safety factor of 100 was used, the probability increased to $1.18-11.5 \%, 1.72-7.35 \%$, and $76.3-96.2 \%$. The results of the JPC analysis indicate that the overall exposure risk of PCP is greater than that of 2,4DCP or 2,4,6-TCP.

Level 4 The probabilities of exceeding pre-established levels of risk obtained from Monte Carlo simulations are given (Fig. 5). For 2,4-DCP, 2,4,6-TCP, and PCP, the exceedance probabilities were $0.16 \%, 0.16 \%$, and near zero for the DBQ of MEC/NOEC $\geq 1$ and $0.16 \%, 0.47 \%$, and $10.26 \%$ for the DBQ of MEC/NOEC $\geq 0.1$, respectively, while the application of a safety factor of 100 , which corresponds the DBQ of MEC/NOEC $\geq 0.01$ resulted in a probabilities of exceedances of $6.06 \%, 1.56 \%$, and $75.74 \%$. The probabilities of exceedances were $50.03 \%, 31.88 \%$, and $85.06 \%$ when a safety factor of 1000 (MEC/NOEC $\geq 0.001$ ) was used. Monte Carlo simulation and the JPC method are different risk characterization modes with the same fundamentals. The European Union, which frequently establishes regulatory-binding quotients, distinguishes between the two methods in regulatory matters. This is due to the fact that Monte Carlo simulation can be used to assess a variety of types of data distributions and data sets even when data do not fit specific distributions, such as the normal probability function (Zolezzi et al. 2005).

The results of all four modes of risk-assessment showed that the risk from the chlorophenols can be ranked as $\mathrm{PCP}>$ $2,4-\mathrm{DCP} \approx 2,4,6$-TCP. While PCP posed the greatest risk, the potential for adverse effects was classified as "low" while 2,4-DCP and 2,4,6-TCP posed negligible risk to aquatic organisms in surface waters of China. However, the risks varied among river basins and PCP posed the greatest ecological risk in the Yangtze, Huaihe, and Pearl Rivers. Pentachlorophenol was used in China as a molluscacide to kill oncomelania, especially in the Yangtze River watershed. Use of PCP as a pesticide in China was banned 1997 but it is still utilized as a wood preservative (Zheng et al. 2000). These uses of PCP could explain its prevalence in the surface waters of China (Gao et al. 2008). The magnitude of 2,4-DCP and 2,4,6-TCP pollution in Northern China were more serious than that in Southern China, possibly because phenoxyacid herbicides, which can 
Fig 3 Probability distribution curves for the exposure concentrations and no observed effect concentrations (NOECs) of three chlorophenols
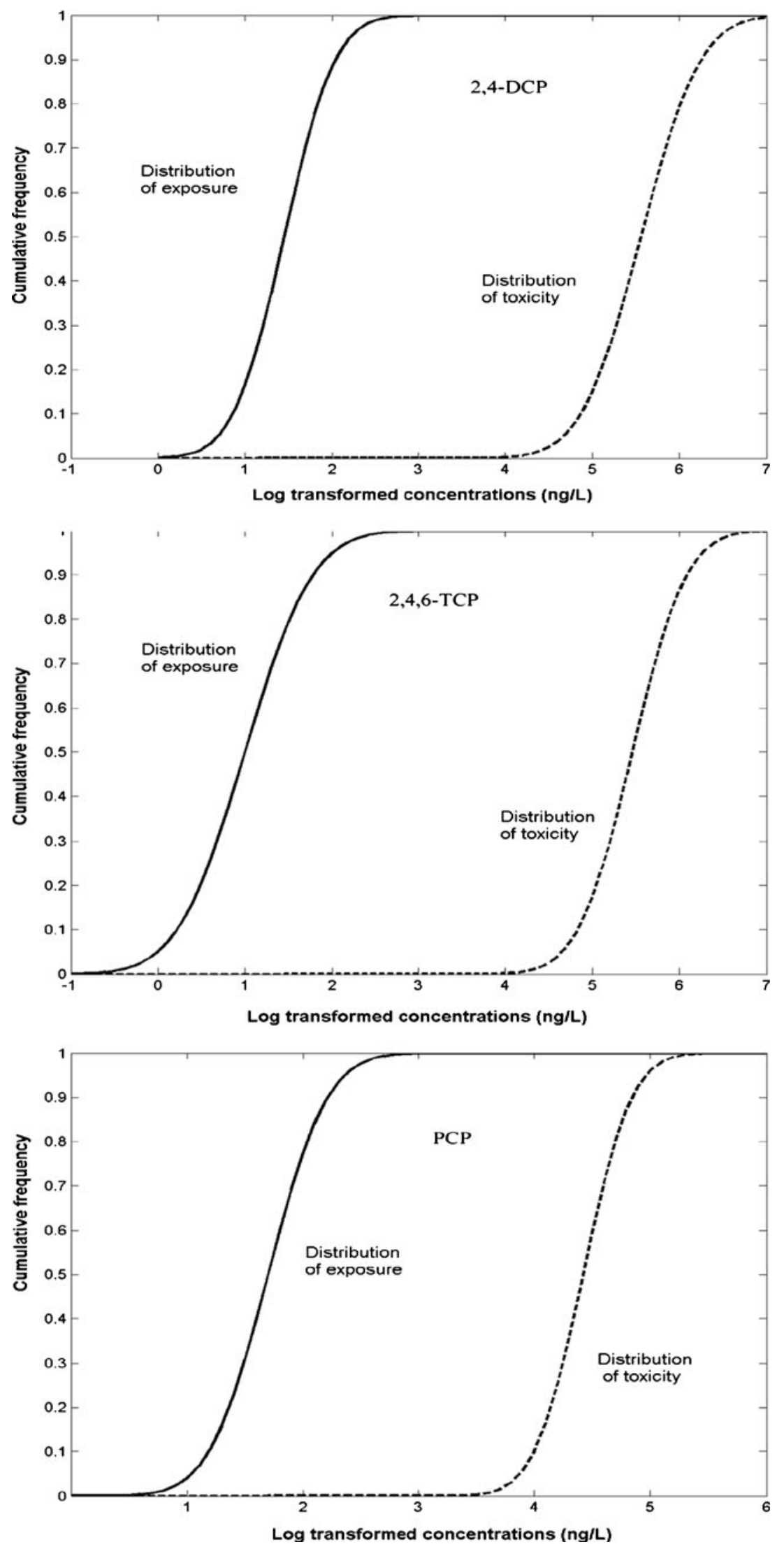


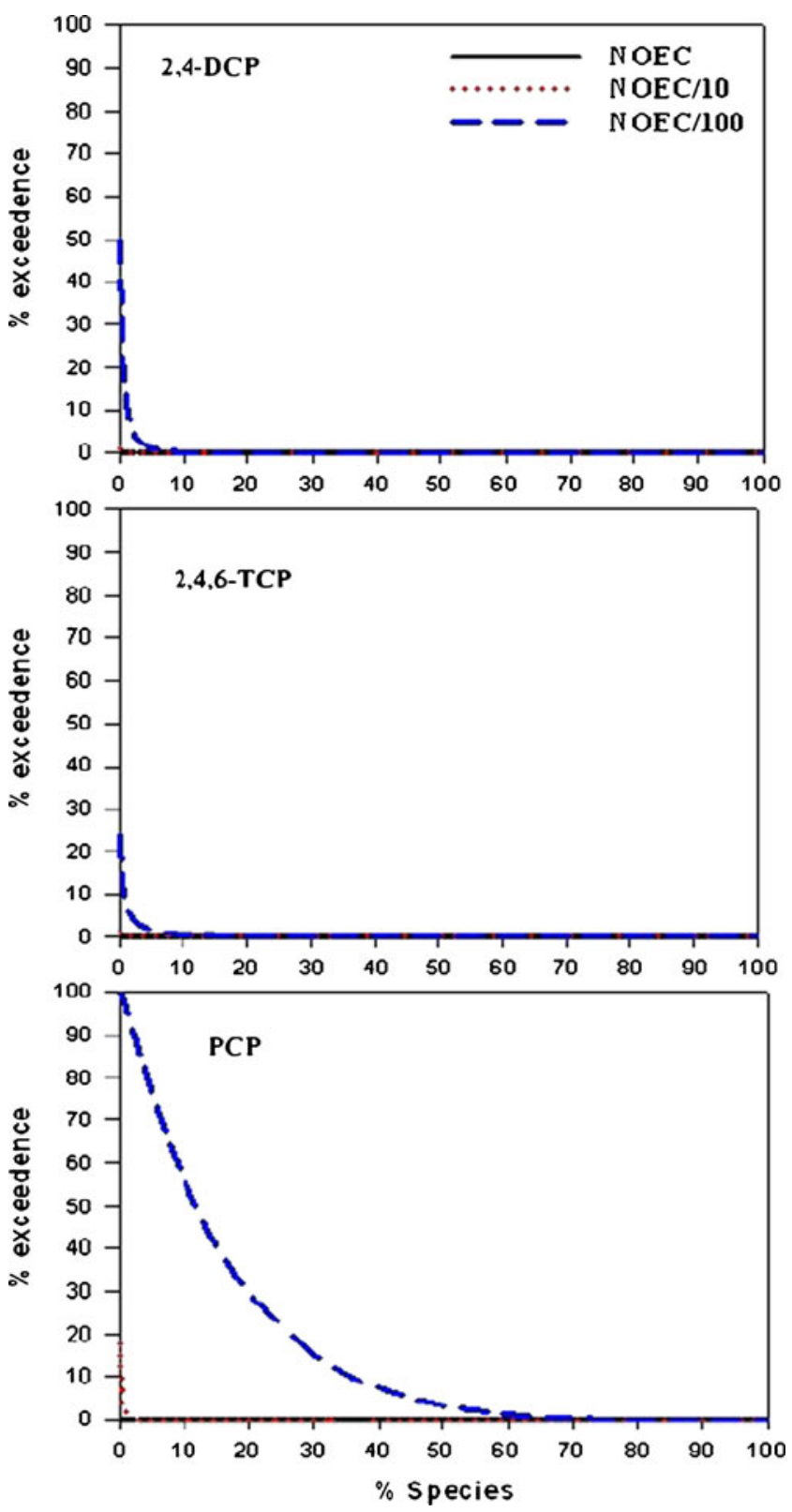

Fig 4 Joint probability curves for ecological risk of three chlorophenols in surface water from China

degrade into 2,4-DCP and 2,4,6-TCP, are used more in Northern China. The watersheds of Northern China are the important agricultural areas with $29.5 \times 10^{6}$ and $30.1 \times 10^{6}$ acres of farmland in the Yellow and Huaihe River areas, respectively. Phenoxyacid herbicides are used throughout these watersheds (Gao et al. 2008).

Methods ranging from deterministic to probabilistic methods are usually recommended for ecological risk assessment, with the probabilistic approach serving to refine the risk estimated after more conservative lower-tier approaches. Results of probabilistic ERAs can provide useful information for risk managers and decision makers.
However, hazard quotients, especially the single-value estimates, still have the advantage of readily identifying chemicals that have a likelihood of producing effects on species. The single-value estimate method is useful as a screening tool that can help to focus risk assessments. The initial estimations found in level 1 of the present study, which showed high HQ values, suggested that a generalized potential risk for the whole area could not be excluded. The higher-tier approaches allowed the estimation of the proportional risk of measured chlorophenol concentrations to aquatic species in Chinese surface waters, even though a large majority of the area contained chlorophenols less than thresholds for toxicity.

Uncertainty in ERA is inevitable even when higher-tier methods are used. Sources of uncertainty in the ERA include: the variability of chlorophenol concentration within a single body of water, the ecological relevance of the toxicity data, and the risk characterization model. In particular, information on spatial and temporal variation in
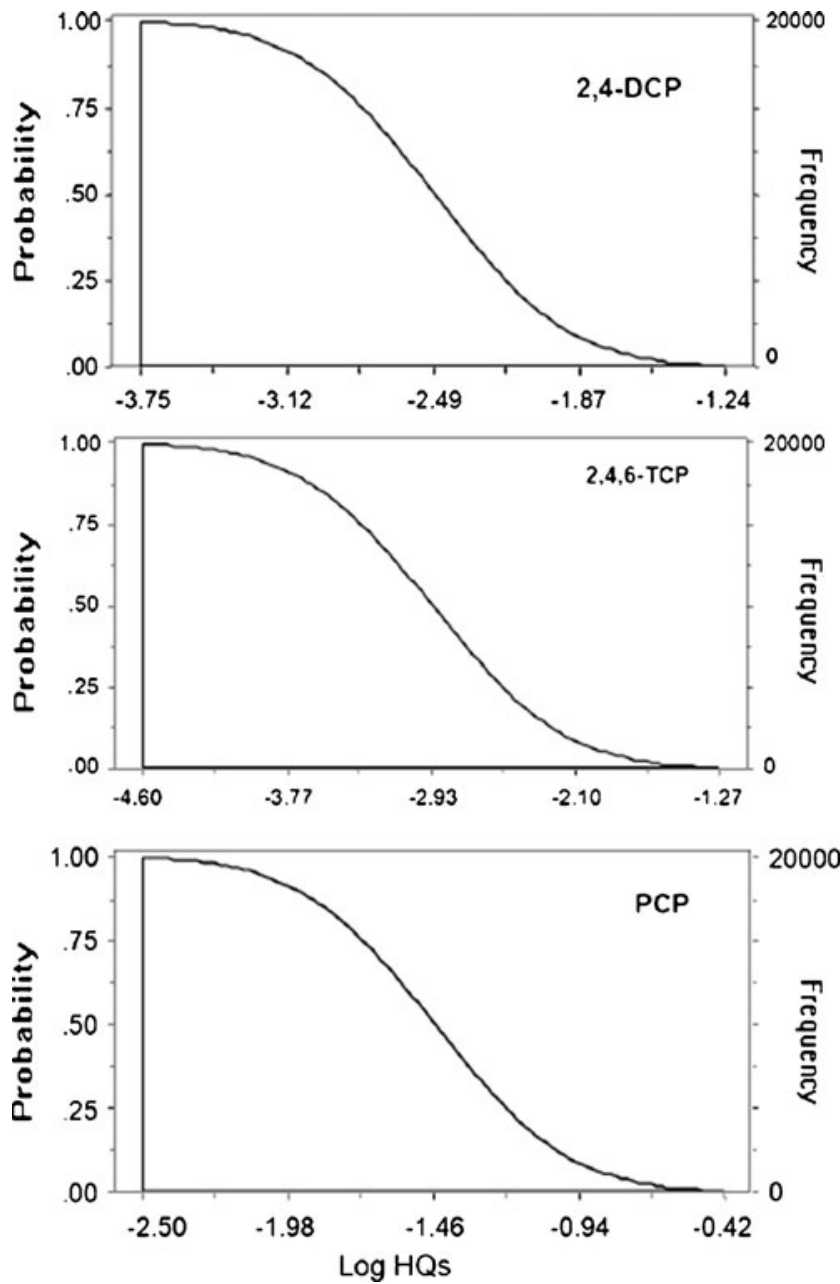

Fig. 5 Exceedance probability of HQs based on 20,000 times Monte Carlo simulation of three chlorophenols 
chlorophenol concentrations was limited, especially for a nationwide monitoring. To more accurately describe exposures, further information needs to be collected to describe concentrations of chlorophenols at various spatial and temporal scales. In the present study, chronic toxicity values for indigenous Chinese aquatic species from different trophic levels were used to decrease uncertainty associated with species-specific responses and to better mimic real-world scenarios of long-term exposure. Chronic toxicities, such as NOECs, are preferable to derive toxicity threshold in ERA (Pennington 2003), but there is a lack of available chronic data, especially for local species for sitespecific ERAs. So, chronic toxicity data for various pollutants for site-specific species are critically needed in order to produce more accurate ecological risk assessments. Also, the lack of consensus on ERA methods precluded effective comparison among calculated risk levels by different risk assessors. Standard methods should be developed and employed by researchers and public agencies to evaluate ecological risk (Wang et al. 2009).

\section{Conclusions}

The results of the study upon which we report here, demonstrate the use of the tiered ERA approach based on nationwide surface water measured concentrations and long-term exposure toxicity data for indigenous Chinese species to analyze the risks posed by three chlorophenols to aquatic ecosystem in China. Probabilistic risk assessment, which can provide reliable predictions for risk managers and decision makers, is considered superior to the screening-level single-value estimate method. However, the results from all levels of the ERA in the tiered framework were consistent. Among the three chlorophenols studied, PCP posed relatively little risk of adverse effects to aquatic organisms in Chinese surface water, while 2,4-DCP and 2,4,6-TCP posed negligible risks. The use of chlorophenols might affect the aquatic organisms and corresponding measures should be taken to minimize ecological risk posed by chlorophenols, especially for PCP.

Acknowledgment This research was financially supported by National Basic Research Program of China (2007CB407301), National Natural Science Foundation of China (20737003), and Ministry of Environmental Protection of the People's Republic of China (201009032). Prof. Giesy was supported by the Canada Research Chair program, an at large Chair Professorship at the Department of Biology and Chemistry and State Key Laboratory in Marine Pollution, City University of Hong Kong, The Einstein Professor Program of the Chinese Academy of Sciences and the Visiting Professor Program of King Saud University.

\section{References}

Aldenberg T, Slob W (1993) Confidence-limits for hazardous concentrations based on logistically distributed Noec toxicity data. Ecotox Environ Safe 25:48-63

Asplund G, Grimvall A (1991) Organohalogens in nature. Environ Sci Technol 25:1346-1350

Bartell SM, Campbell KR, Lovelock CM, Nair SK, Shaw JL (2000) Characterizing aquatic ecological risks from pesticides using a diquat dibromide case study III. Ecological process models. Environ Toxicol Chem 19:1441-1453

Besser JM, Wang N, Dwyer FJ, Mayer FL, Ingersoll CG (2005) Assessing contaminant sensitivity of endangered and threatened aquatic species: part II. Chronic toxicity of copper and pentachlorophenol to two endangered species and two surrogate species. Arch Environ Contam Toxicol 48:155-165

Brain RA, Sanderson H, Sibley PK, Solomon KR (2006) Probabilistic ecological hazard assessment: evaluating pharmaceutical effects on aquatic higher plants as an example. Ecotox Environ Safe 64:128-135

Brix KV, DeForest DK, Adams WJ (2001) Assessing acute and chronic copper risks to freshwater aquatic life using species sensitivity distributions for different taxonomic groups. Environ Toxicol Chem 20:1846-1856

Carey J, Fox M, Hart J (1988) Identity and distribution of chlorophenols in the North Arm of the Fraser River estuary. Water pollution research journal of Canada Burlington ON 23:31-44

Chapman PM, Fairbrother A, Brown D (1998) A critical evaluation of safety (uncertainty) factors for ecological risk assessment. Environ Toxicol Chem 17:99-108

Chen CS (2005) Ecological risk assessment for aquatic species exposed to contaminants in Keelung River, Taiwan. Chemosphere 61:1142-1158

Czaplicka M (2004) Sources and transformations of chlorophenols in the natural environment. Sci Total Environ 322:21-39

Davies PE, Cook LSJ, Goenarso D (1994) Sublethal responses to pesticides of several species of Australian fresh-water fish and crustaceans and rainbow-trout. Environ Toxicol Chem $13: 1341-1354$

ECB (2003) Technical guidance document on risk assessment in support of commission directive 93/67/EEC on risk assessment for new notified substances, commission regulation (EC) no. 1488/94 on risk assessment for existing sunstances, derective 98/ 8/EC of the European Parliament and of the Council concerning the placing of biocidal products on the market. Part II. Environmental Risk Assessment. European Chemicals Bureau, European Commission Joint Research Center, European Communities.

ECOFRAM (1999) ECOFRAM Terrestrial Final Draft Reports. USEPA, http://www.epa.gov/oppefed1/ecorisk/terrreport.pdf.

Gao JJ, Liu LH, Liu XR, Zhou HD, Huang SB, Wang ZJ (2008) Levels and spatial distribution of chlorophenols 2,4-dichlorophenol, 2,4,6-trichlorophenol, and pentachlorophenol in surface water of China. Chemosphere 71:1181-1187

Ge JC, Pan JL, Fel ZL, Wu GH, Giesy JP (2007) Concentrations of pentachlorophenol (PCP) in fish and shrimp in Jiangsu Province, China. Chemosphere 69:164-169

Giesy JP, Solomon KR, Coats J, Dixon KR, Giddings JM, Kenaga EE (1999) Chlorpyrifos: ecological risk assessment in North American aquatic environments. Rev Environ Contam Toxicol 160:1-129

Grimvall A (1995) Evidence of naturally produced and man-made organohalogens in water and sediments. In: de Leer EWB (ed) Naturally-produced organohalogens. Kluwer, Dordrecht, p 3 
Hall LW, Scott MC, Killen WD, Unger MA (2000) A probabilistic ecological risk assessment of tributyltin in surface waters of the Chesapeake Bay watershed. Hum Ecol Risk Assess 6:141-179

Hunt J, Birch G, Warne MSJ (2010) Site-specific probabilistic ecological risk assessment of a volatile chlorinated hydrocarbon-contaminated tidal estuary. Environ Toxicol Chem 29:1172-1181

Isnard P, Flammarion P, Roman G, Babut M, Bastien P, Bintein S, Essermeant L, Ferard JF, Gallotti-Schmitt S, Saouter E, Saroli M, Thiebaud H, Tomassone R, Vindimian E (2001) Statistical analysis of regulatory ecotoxicity tests. Chemosphere 45:659-669

Jin XW, Zha JM, Xu YP, Wang ZJ, Satyanarayanan SK (2011a) Derivation of aquatic predicted no effect concentration (PNEC) for 2,4-dichlorophenol: comparing native species data with nonnative species data. Chemosphere 84:1506-1511

Jin XW, Zha JM, Xu YP, Wang ZJ, Giesy JP, Richardson KL (2011b) Derivation of predicted no effect concentrations (PNEC) for 2,4,6-trichlorophenol based on Chinese resident species. Chemosphere. doi:10.1016/j.chemosphere.2011.08.040

Jin XW, Zha JM, Xu YP, Giesy JP, Wang ZJ (2011c) Toxicities of pentachlorophenol to native aquatic species in the Yangtze River. Environ Sci Pollut Res. doi:10.1007/s11356-011-0594-1

Klimisch HJ, Andreae M, Tillmann U (1997) A systematic approach for evaluating the quality of experimental toxicological and ecotoxicological data. Regul Toxicol Pharm 25:1-5

Pennington DW (2003) Extrapolating ecotoxicological measures from small data sets. Ecotox Environ Safe 56:238-250

Rawn DFK, Halldorson THJ, Woychuk RN, Muir DCG (1999) Pesticides in the Red River and its tributaries in southern Manitoba: 1993-95. Water Qual Res J Can 34:183-219

Roex EWM, Van Gestel CA, Van Wezel AP, Van Straalen NM (2000) Ratios between acute aquatic toxicity and effects on population growth rates in relation to toxicant mode of action. Environ Toxicol Chem 19:685-693

SETAC (1994) Pesticide risk and mitigation. Final Report of the Aquatic Risk Assessment and Mitigation Dialog Group. SETAC Foundation and Environmental Education, Pensacola, FL, 220pp.

Solomon KR (1996) Overview of recent developments in ecotoxicological risk assessment. Risk Analysis 16:627-633

Solomon KR, Sibley P (2002) New concepts in ecological risk assessment: where do we go from here? Mar Pollut Bull 44:279-285

Solomon K, Giesy J, Jones P (2000) Probabilistic risk assessment of agrochemicals in the environment. Crop Prot 19:649-655

USEPA (1991) Water Quality Criteria Summary, Ecological Risk Assessment Branch (WH-585) and Human Risk Assessment
Branch (WH-550D). in: Health and Ecological Criteria Division, U. (Ed.). USA, Washington, DC

Veningerova M, Prachar V, Kovacicova J, Uhnak J (1998) Levels of chlorinated phenols in Danube river water. Fresen Environ Bull 7:224-231

Wang XL, Tao S, Dawson RW, Xu FL (2002) Characterizing and comparing risks of polycyclic aromatic hydrocarbons in a Tianjin wastewater-irrigated area. Environ Res 90:201-206

Wang B, Yu G, Huang J, Yu YJ, Hu HY, Wang LS (2009) Tiered aquatic ecological risk assessment of organochlorine pesticides and their mixture in Jiangsu reach of Huaihe River, China. Environ Monit Assess 157:29-42

Wheeler JR, Grist EPM, Leung KMY, Morritt D, Crane M (2002) Species sensitivity distributions: data and model choice. Mar Pollut Bull 45:192-202

Xia Q, Chen YQ, Liu XB (2004) Water quality criteria and standards. Standard Press in China, Beijing

Yin DQ, Hu SQ, Jin HJ, Yu LW (2003a) Deriving freshwater quality criteria for 2,4,6-trichlorophenol for protection of aquatic life in China. Chemosphere 52:67-73

Yin DQ, Jin HJ, Yu LW, Hu SQ (2003b) Deriving freshwater quality criteria for 2,4-dichlorophenol for protection of aquatic life in China. Environ Pollut 122:217-222

Zha JM, Wang ZJ, Schlenk D (2006) Effects of pentachlorophenol on the reproduction of Japanese medaka (Oryzias latipes). ChemBiol Interact 161:26-36

Zhang ZL, Hong HS, Zhou JL, Yu G, Chen WQ, Wang XH (2002) Transport and fate of organochlorine pesticides in the River Wuchuan, Southeast China. J Environ Monitor 4:435-441

Zhang JF, Shen H, Wang XR, Wu JC, Xue YQ (2004) Effects of chronic exposure of 2,4-dichlorophenol on the antioxidant system in liver of freshwater fish Carassius auratus. Chemosphere 55:167-174

Zheng MH, Zhang B, Bao ZC, Yang H, Xu XB (2000) Analysis of pentachlorophenol from water, sediments, and fish bile of Dongting lake in China. B Environ Contam Tox 64:16-19

Zhong WJ, Wang DH, Xu XW, Luo QA, Wang BY, Shan XQ, Wang ZJ (2010) Screening level ecological risk assessment for phenols in surface water of the Taihu Lake. Chemosphere 80:998-1005

Zhou JL, Hong H, Zhang Z, Maskaoui K, Chen W (2000) Multi-phase distribution of organic micropollutants in Xiamen Harbour, China. Water Res 34:2132-2150

Zolezzi M, Cattaneo C, Tarazona JV (2005) Probabilistic ecological risk assessment of 1,2,4-trichlorobenzene at a former industrial contaminated site. Environ Sci Technol 39:2920-2926 